\title{
Produção de Corpos Generificados em um Bloco Cirúrgico: Uma Análise pelo Trabalho como Atividade
}

\author{
Production of Bodies Generated in a Surgical Ward: \\ An Analysis by Work as an Activity \\ Producción de Cuerpos Generados en uma Unidad Quirúrgica: \\ Una Análisis por Trabajo como Actividad \\ Renata da Silveira Borstmann \\ Fernanda Spanier Amador \\ Universidade Federal do Rio Grande do Sul (UFRGS), Porto Alegre, RS, Brasil
}

\begin{abstract}
Resumo
Neste artigo, analisamos o trabalho em saúde em um bloco cirúrgico a partir do referencial teóricoda Clínica da Atividade, atentando para a especificidade da performatividade do gênero por entre esta experiência. Para tanto, produzimos um percurso transverso do ponto de vista do método, operando por entre Clínica da Atividade e pistas do Método Cartográfico, realizando, ainda, articulações com a proposta praxiográfica. As análises apontam que, apesar das fortes prescrições que compõem o trabalho em um bloco cirúrgico, os trabalhadores e trabalhadoras problematizam as normas de trabalho e de gênero nas situações laborais, produzindo estilizações. É na atividade que as normas de trabalho, e também de gênero, são colocadas em questão abrindo brechas e críticas a modelos regulatórios, e também violentos, que ancoram, por vezes, as práticas em saúde. A partir dessa pesquisa, apontamos a importância de produzir estudos relativos à produção do gênero em meio aos processos operativos do trabalho.
\end{abstract}

Palavras-chave: Trabalho em saúde; Atividade; Performatividade; Gênero; Normatividade.

\begin{abstract}
In this article, we analyzed the health work in surgical ward based on the theoretical references of the Clinic of Activity, taking into account specificity of gender performativity among this experience. For this purpose, we produced a transversal path from the point of view of the method, operating methodologically between the Clinic of Activity and clues from the Cartographic Method, also performing articulations with the praxiographic. The analyzes point out that, despite the strong prescriptions that make up the work in surgical ward, the workers problematize labor and gender norms in work situations, producing stylizations. It's in the activity that work norms, as well as gender, they are called into question, opening loopholes and criticisms of regulatory models, and also violent, that sometimes anchor health practices. This research indicates the importance of further studies towards the production involving gender and labor processes.
\end{abstract}

Keywords: Health work, Activity, Performativity, Gender, Normativity. 


\section{Resumen}

En este artículo analizamos el trabajo en salud en una Unidad Quirúrgica de un Hospital a partir de los referentes teóricos de la Clínica de Actividad, prestando atención a La especificidad del performatividad de género em esta experiencia. Para eso, producimos un recorrido transversal desde el punto de vista del método, operando entre la Clínica de Actividad y las pistas del Método Cartográfico, realizando también articulaciones com La propuesta praxiográfica. Los análisis muestran que, a pesar de las fuertes prescripciones que conforman el trabajo en una unidad quirúrgica, los trabajadores y trabajadoras problematizan las normas laborales y de género em las situaciones laborales, produciendo estilizaciones. Es em la actividad donde se cuestionan las normas laborales, así como el género, abriendo lagunas y críticas a modelos regulatorios, y también violentos, que en ocasiones anclanlas prácticas de salud. A partir de esta investigación, señalamos La importancia de producir estudios relacionados com la producción de género enmedio de los procesos operativos del trabajo.

Palabras clave: Trabajo de salud; Actividad; Performatividad; Género; Normatividad

\section{Trabalho e gênero: tecitura de uma problemática de pesquisa}

Neste artigo, apresentamos aspectos de uma pesquisa ${ }^{1}$ realizada com trabalhadores e trabalhadoras da saúde do bloco cirúrgico de um hospital localizado no sul do Brasil, quando colocamos em questão o atravessamento de gênero ${ }^{2}$ na produção da gestão e do cuidado no trabalho em saúde.

Considerando a existência de um atravessamento de gênero na produção da gestão e do cuidado em saúde e que a incorporação de modos de subjetivar corpos sexuados se reverte em práticas específicas de produção de saúde, a abordagem de tais questões pela análise do trabalho como atividade, ou seja, pela Rev. Polis e Psique, 2021; 11(3): 184 - 206 análise das microgestões que ocorrem entre o Trabalho Prescrito e o Trabalho real (Yves Clot, 2010), emerge como caminho relevante. Por um lado, pela riqueza de elementos analíticos aí implicados e por outro, pela escassez de estudos realizados nesta perspectiva ${ }^{3}$.

Interessa-nos compreender como ocorre a produção do gênero ${ }^{4}$ no ato do trabalho, pelo trabalho como atividade, mais especificamente pelo constante debate de valores e normas que permeia o exercício do trabalho como atividade. Assim, estar em atividade é estar imerso em um processo normativo, implicando, assim, numa dimensão performativa na atividade.

Tendo em vista que operamos no modo como os trabalhadores e 
trabalhadoras se constituem através da ação em suas práticas laborais, encontramo-nos com a perspectiva teórica da filósofa Judith Butler (2003), a qual propõe pensar o gênero a partir da teoria da performatividade. Tal perspectiva compreende que a produção de sujeitos sexuados ocorre por entre regimes de normas sociais e possibilidades de agenciamentos. Nesse sentido, a materialidade dos corpos é constituída através de atos performativos e práticas reiterativas e citacionais, nos quais $\mathrm{o}$ sujeito é efeito de verdades de tramas de saber, poder e discurso, que são produzidos de maneira histórica e cultural. Diante disso, são os atos corporais e os atos de fala que visam conformar o corpo às normas, por intermédio da constante repetição e reiteração. Entretanto, por serem repetíveis, essas normas também são passíveis de reinvenção, de ressignificação.

A perspectiva da performatividade de gênero nos permite olhar para dimensão corporal dos trabalhadores e trabalhadoras, no sentido de pensar no modo como se constituem na atividade, bem como no modo como sua inserção, seus atos, suas práticas, suas falas, os produzem enquanto sujeitos por entre as microgestões do trabalho, enfrentando as infidelidades do meio $\mathrm{e}$ as relações de poder $\mathrm{e}$ normatividades aí presentes. Além disso, a ideia de performatividade ajuda-nos a pensar que o sujeito nunca é constituído totalmente, uma vez que ele não é anterior a um fazer, pois se constitui a partir da ação.

Transitando pelo pensamento de Clot e Butler, operamos pelo que chamamos de duas dimensões de performatividade: da atividade e de gênero, de maneira que fomos levadas ao encontro de Annemarie Mol, autora que se ocupa da performatividade sob o ponto de vista da materialidade de corpos (humanos e não humanos). A contribuição da etnógrafa e filósofa nos possibilita analisar os modos como a realidade vai sendo produzida e ordenada em arranjos múltiplos e heterogêneos, investigando as conexões parciais e locais entre agentes e objetos. $\mathrm{O}$ interesse, portanto, não está na estrita descrição do fazer, mas em como a realidade é performada pelos diferentes atores. Desse modo, tal concepção nos parece útil na tentativa de operar no modo como os trabalhadores e trabalhadoras vão se "fazendo" em suas práticas, preocupando-se com o aqui e agora, no modo como se constituem a partir da ação. Nessa dissertação, Mol (2002) contribui, 
sobretudo, com a possibilidade de abertura de uma vertente de investigação metodológica relativa ao método da Praxiografia em articulação com métodos em Clínica da Atividade.

Assim, exploramos por entre a análise do trabalho em saúde enquanto atividade, a especificidade da performatividade de gênero por entre as microgestões no trabalho como atividade em um bloco cirúrgico de um hospital com a categoria de técnicos e técnicas de enfermagem. Considerando-se a saúde no e pelo trabalho como estando relativa à possibilidade de expansão da potência de agir $^{5}$ trata-se, nesta pesquisa, de, pela experiência do trabalho enquanto atividade, acessar a zona problemática da questão de gênero, analisando a peculiaridade da performatividade implicada na própria performatividade do ato do trabalho em saúde.

Nessa direção, o trabalho concebido enquanto atividade nos fornece elementos importantes para a análise da ação em situação de trabalho e para problematizarmos o modo com os técnicos e técnicas de enfermagem de um bloco cirúrgico operam as microgestões do trabalho no cotidiano levando-se em conta a performatividade de gênero por entre esta operação.
Ocupamo-nos nesta pesquisa das especificidades do bloco cirúrgico: setor recluso e fechado, onde circulam somente profissionais e pacientes prestes a se submeter a um procedimento cirúrgico. A passagem do paciente é rápida, em que a montagem e desmontagem dos equipamentos nas salas cirúrgicas funciona como uma espécie de "linha de produção". Cada profissional tem um contato diferenciado com o corpo do paciente, o que confere um status nessa relação já que o contato "consciente" do paciente ocorre com os técnicos e técnicas de enfermagem e com o anestesiologista, enquanto que com os médicos cirurgiões os pacientes já se encontram anestesiados e, portanto, a mercê da manipulação cirúrgica.

\section{Perform(atividade)s: articulações entre o trabalho como atividade e o pensamento de Judith Butler}

Clot (2010) desenvolveu pesquisas analisando a distância sempreexistente entre o Trabalho Prescrito e o Trabalho Realizado e, para isto, parte do conceito deatividade situada, ou seja, aquela que efetivamente ocorre no cotidiano de trabalho. Dessa forma, o trabalho vivo em ato é o objeto principal e, mais especificamente, aatividade: ambas as 
dimensões desenvolvidas de modo singularizado em suas pesquisas.

Para Clot (2010) e os pesquisadores e pesquisadoras da Clínica da Atividade, seguindo a tradição francesa de análise do trabalho, a atividade como sempre, mais do que a atividade realizada, é passível de descrição para fins de análise, pois abarca conflitos oriundos do processo. A atividade exige a mobilização física e psíquica do trabalhador e trabalhadora, frente a um meio em constante variação, indo para além apenas do gesto realizado, passível de observação direta e mensurável, definindose, portanto, pelas operações manuais e intelectuais postas em prática a cada momento pelo trabalhador e trabalhadora a fim de atender seus objetivos, que extrapolam aqueles prescritos pela organização do trabalho, em vista de um meio que se modifica constantemente.

Analisar o trabalho como atividade sob essa perspectiva implica considerar mais do que o posto de trabalho e suas tarefas, implica levar em conta uma história em desenvolvimento. Ela é um processo sempre inconcluso, inesperado, variável, tendo como unidade de ação o tripé si "si mesmo, objeto de trabalho e os outros". A atividade é sempre dirigida. Ela se dirige a um destinatário, a alguém, ainda que se trabalhe sozinho ou sozinha. É preocupando-se consigo mesmo, com o objeto de trabalho e com os outros que o trabalhador e trabalhadora se insere em uma atividade laboral (Clot, 2010).

$$
\text { Considerando que o que se }
$$
expressa no trabalho como atividade não é o resultado de uma ação anterior, mas a potência de produção no e pelo trabalho, pensamos nas conexões possíveis entre o trabalho como atividade e o conceitoferramenta da performatividade de gênero desenvolvido por Butler (2003). Tal articulação nos parece relevante, pois tomar o trabalho como atividade implica tomá-lo desde a perspectiva de uma performatividade e, além disso, contribui para analisar o modo como os trabalhadores e trabalhadoras se produzem de modo generificado pela experiência do trabalho como atividade.

Para Butler (2003), o marcador gênero refere-se a uma produção no âmbito de discursos culturais e subculturais, que são responsáveis pela criação do nosso sexo, nossa sexualidade, nosso gênero. A filósofa utiliza, então, o conceito de performatividade, que remete a um ato sem um ator, contestando a noção de um sujeito anterior a ação. Nesse sentido, o gênero é performativo, pois é através da reiteração e 
repetição de atos que se consolida o sujeito e se constitui o gênero, como se fosse algo natural, ou seja, um efeito de performances repetidas que se reatualizam através dos discursos históricos e culturais.

Embora muitas perfomatividades sejam altamente reguladas, de acordo com AlastairPennycook (2007) há espaço para que o sujeito seja capaz de fazer escolhas. Butler (2003), nesse sentido, discute a noção de agência, sendo essa a possibilidade de construir e criar novas performatividades. Para a filósofa, a possibilidade de agência é compreendida como a capacidade de ação, que se encontra na sujeição e na subordinação, ou seja, a mudança acontece dentro da própria dinâmica do poder, que pode reiterar formas de ressignificação, produzindo novos efeitos. Clot (2010) indica também o termo agência para definir o conceito de poder de agir em sua obra "Trabalho e Poder de agir" (p. 35). Para o autor o poder de agir na atividade só consegue se desenvolver quando assume uma responsabilidade coletiva de ação que garanta uma capacidade real de escolha para os trabalhadores e trabalhadoras, assumindo, portanto, um caráter de criação no e pelo trabalho. A agência, em Clot (2010) remete, portanto, a uma capacidade de ação que coloca em jogo a normativa já Rev. Polis e Psique, 2021; 11(3): 184 - 206 estabelecida no trabalho, bem como a possibilidade de agenciar novas normas, que dependerão da afetação dos corpos, de expandir ou não a potência de ação. A agência diz respeito, portanto, ao processo de mudança, de desestabilização, como possibilidade de colocar em questão, inclusive, aquilo que é da ordem do gênero envolvido no ato do trabalho. Assim como, para que o gênero profissional não necrose, para que possa estilizar, produzindo saúde e seguir sendo normativo faz-se necessário agenciar-se coletivamente na produção da diferença.

Butler (2003) compreende que a estilização corpórea do gênero pode ser considerada como um processo intersubjetivo produzido na negociação entre as determinações dos processos performativos já instaurados e a possibilidade de agenciar outras performances. Deste modo, podemos pensar que os trabalhadores e trabalhadoras em seus espaços laborais se engajam em performances que repetem modelos identitários profissionais construídos de maneira histórica e cultural, constitutivos de determinados gêneros profissionais e discurso, o que se refere ao performativo (Pennycook, 2007). Mas, por outro lado, têm a possibilidade de, a partir do uso que fazem de seus saberes, de seus 
corpos, vivenciar novas performances profissionais incorporando novos contornos estilísticos ao gênero, o que se refere à performatividade. Contudo, se a noção de gênero pode ser útil para pensar a articulação entre um nível situado e emergente de performance em um contexto social amplo, a noção de gênero profissional (Clot, 2010) pode contribuir para a compreensão da especificidade da atividade profissional do trabalhador e da trabalhadora, na medida em que busca dar conta de todo um contexto discursivo, de ações corporais, de gestos profissionais, que de algum modo tipificam ou estilizam as operações de trabalho.

Clot (2006) desenvolve os conceitos de gênero profissional e estilo inspirado na obra de Mikhail Bakhtin no campo da linguagem - para o campo do trabalho, como instrumentos para uma clínica da atividade. Estes conceitos contribuem para operar no plano de produção das normas e dos valores nos meios coletivos de trabalho.

$\mathrm{O}$ gênero profissional constitui um referencial ao qual o trabalhador ou trabalhadora recorre frente às variabilidades que se apresentam no meio e que permitem analisarmos os coletivos de trabalho considerando que há um dispositivo aberto de regras transpessoais, historicamente construído, ao qual esse coletivo refere-se na relação com os objetos e nas relações entre os trabalhadores e trabalhadoras. Este referencial comum, pelo qual o gênero profissional é constituído e constituinte, não deve ser compreendido como um somatório de referências individuais, como se fosse o todo do qual os indivíduos seriam partes, mas como um componente social, ou genérico, no sentido de que o todo a ninguém pertence. É considerado como uma espécie de "corpo intermediário" (Clot, 2006), que possibilita, por exemplo, que trabalhadores e trabalhadoras que não se conhecem possam ser capazes de realizar um objetivo de um contexto complexo de trabalho, por possuírem um gênero da atividade semelhante que lhes facilita resolver tal situação colocada.

Se, por um lado, o gênero profissional, é um potente recurso para a atividade e suporte do desenvolvimento do poder de agir, por outro é na própria atividade que cada trabalhador ou trabalhadora garante a contínua vitalização do gênero, indicando sua estabilidade sempre provisória. Clot (2010) constrói o conceito de estilo profissional como um 
instrumento quese expressa em estilo pessoal, mas se produz em uma zona coletiva, de forças, de passagem, ou que emerge do coletivo. Do gênero profissional, daquilo que já se fez e assumiu como modo de trabalhar, mas também de virtualidades enquanto forças em curso de atualização que possibilitam outros modos de trabalhar, possibilitando, assim, a permanente potência de transformação do ofício.

Dialogando com Butler, podemos dizer que o gênero da atividade é a estilização repetida de atos profissionais que passam a valer como norma, seja de modo explícito ou implícito. Os trabalhadores e trabalhadoras podem recriar os gêneros na medida em que criam “condições de ação que levam elementos do contexto e de sua conduta a se associar numa relação que oferece uma saída nova para a situação vivida" (Faita, 2004, p. 69).

$\mathrm{O}$ gênero profissional é aquilo que não deixa o trabalhador errar sozinho (Clot, 2006). A errância pode ser considerada tanto no sentido de falha na execução, como no sentido de estilização na atividade ou produção de outros modos singulares de agir diante dos imprevistos. Assim, os estilos seriamo nível mais elevado do poder de agir, a própria inventividade do trabalho possibilitada pelos gêneros profissionais.

Considerando que a noção do gênero profissional diz respeito aos saberes informais gerados na experiência do trabalho e compartilhado pelos trabalhadores e pelas trabalhadoras, formando uma memória coletiva do ofício $^{6}$, no qual estão inscritos os saberes, a memória dos fracassos, as perguntas sem resposta, aquilo que pode ser realizável ou não (Clot, 2010), como podemos pensar a disputa de gênero (Butler, 2003) no ato do trabalho que se concretiza com o estoque/patrimônio para agir? Como podemos pensar o debate daquilo que os trabalhadores e trabalhadoras fazem e aquilo que ele não chega a fazer, suas hesitações, seus impedimentos, os debates com aquilo que deveria ser feito sob o prisma da performatividade de gênero no trabalho em saúde?

Tendo em vista que a atividade é um processo em constante devir, que abarca possibilidades e impossibilidades com as que o trabalhador ou trabalhadora se depara para dar conta de realizar alguma tarefa, indagamos: como os processos normativos e renormativos do trabalho podem perturbar os processos performativos do gênero, produzindo, assim, a possibilidade de agenciar novas 
performances de gênero produzindo a expansão do poder de agir no e pelo trabalho?

Se a contribuição de Butler poderá auxiliar para posicionar o modo como os trabalhadores e trabalhadoras são constituídos em sua dimensão generificada em meio a relações de poder, e no caso deste estudo, no modo como os trabalhadores e trabalhadoras da saúde se constituem em meio à performatividade de gênero na atividade, consideramos relevantes as contribuições da noção de performance, desenvolvida por Mol ainda que a autora não se ocupe da questão do gênero -, o que nos possibilita um olhar, também, sobre a materialidade dos corpos, para além de sua dimensão discursiva. Tais contribuições nos colocam instigantes questões no que se refere ao ponto de vista analítico do trabalho como atividade.

$\begin{array}{lllrr}\text { Articulações } & \text { entre } & \text { trabalho } & \text { como } \\ \text { atividade e } & \text { o } & \text { conceito } & \text { de } \\ \text { performatividade } & \text { desenvolvido } & \text { por }\end{array}$
Annemarie Mol

Considerando o trânsito por entre a análise do trabalho como atividade e a especificidade da performatividade de gênero nessa dinâmica, encontramo-nos com a produção da autora feminista Annemarie Mol (2002), na qual o interesse pelas práticas e pela ação coloca-nos instigantes questões do ponto de vista do desenvolvimento conceitual a respeito de sua produção, especialmente, ao campo de análise do trabalho como atividade.

Os estudos de Mol contribuem para as pesquisas em ciências sociais no sentido de proporem uma virada para a prática, ou seja, propõe que as ciências sociais se dediquem a investigar as práticas cotidianas. Para ela, a realidade não é algo dado a priori, mas sim efeito das práticas, ou ainda, das práticas que são performativas, ou seja, que fazem existir realidades. Considera também que as realidades são múltiplas, heterogêneas, e que são articuladas como práticas com atores humanos e não humanos. Como consequência, para Mol, conhecer não é questão de representar o real, mas envolve o engajar-se, manejar e interferir nas práticas no ponto em que forma realidades (Marcia Oliveira Moraes \& Arendt, 2013).

A noção de realidade desenvolvida por Mol é entendida, portanto, como múltipla (tendo uma forma que pode ser feita de diferentes maneiras), e sendo assim, a realidade se faz na performance, tendo em vista que ao mudar o lugar de 
interesse, muda-se a performance da realidade. A autora compreende que a realidade é manipulada por uma série de instrumentos, no curso de uma série de práticas, porém, o objeto enquanto parte de distintas atividades, varia de um lugar para outro, sendo este objeto espesso, opaco e com peso. Nesse sentido, na performance, a carnalidade, a opacidade e o peso não são atributos de um objeto único com uma essência e de uma realidade única escondida. A autora considera que em vez de atributos ou aspectos, são diferentes versões que os instrumentos ajudam a performar. São objetos diferentes, mas que ao se relacionarem entre si, "são formas múltiplas da realidade - da realidade em si” (Mol, 2007, p. 66).

Sendo assim, Mol (2002) considera a necessidade de uma Praxiografia que descreva as práticas que estão sendo performadas, como elas estão sendo feitas. A materialidade, portanto, depende de tudo e de todos ou todas que são ativados enquanto algo está sendo praticado. Os pressupostos da fílósofa nos indicam uma importante contribuição para olhar como, na prática, os trabalhadores e trabalhadoras estão se performando em sujeitos por entre a dimensão discursiva do gênero no trabalho em ato, a partir do encontro com os diferentes atores que se articulam no Rev. Polis e Psique, 2021; 11(3): 184 - 206 hospital, os quais produzem múltiplas realidades e materialidades. Nesse sentido, a noção de performance de Mol aproximase do conceito do trabalho como atividade, no sentido de olhar como os trabalhadores e trabalhadoras estão se fazendo na processualidade do trabalho, no modo como o trabalho está sendo feito na prática, convocando assim, para experimentação concreta do mundo para a análise do trabalho como atividade.

\section{Estratégia metodológica: por entre Clínica da Atividade, Pistas do Método Cartográfico e Praxiografia}

Para a produção das análises da pesquisa com os trabalhadores e trabalhadoras, nos colocamos no desafio de produzir um percurso transverso, do ponto de vista do método, por entre aspectos metodológicos em Clínica da Atividade, pistas do Método Cartográfico e Praxiografia para o acesso da análise do trabalho como atividade de técnicos e técnicas de enfermagem de um bloco cirúrgico, colocando em questão a performatividade de gênero implicada no e pelo exercício do trabalho como atividade.

$$
\text { Para acessar a atividade é }
$$
necessário criar condições que possibilitem um plano de análise com os trabalhadores 
e trabalhadoras cujo foco reside na incessante (re)criação dos modos de trabalhar, o que exige o emprego de métodos que possibilitem acompanhar processos, e não representar uma realidade dada (Laura Pozzana de Barros \& Virginia Kastrup, 2009). Diante disso, encontramos no Método Cartográfico, pistas para uma pesquisa que se propõe a tomar o trabalho enquanto atividade, em sintonia com pesquisadores brasileiros e pesquisadoras brasileiras ${ }^{7}$ que vêm produzindo inflexões entre a Clínica da Atividade e as formulações de Gilles Deleuze e Felix Guattari (1995).

Perante as incertezas que compuseram o percurso da pesquisa, apostamos na experiência de habitar o território existencial do trabalho em saúde no hospital investindo na produção de um ethosda confiança (Sade; Ferraz; Jerusa Machado da Rocha, 2013), tendo em vista produzir uma demanda de análise com os trabalhadores e trabalhadoras e a constituição de um coletivo de trabalhadores e trabalhadoras.

Chegamos ao hospital sem termos uma área ou categoria específica delimitada previamente. Após a aprovação do Comitê de Ética em Pesquisa do hospital, tivemos a nossa entrada pela via do Setor de Desenvolvimento Humano ${ }^{8}$ e fomos recebidas por duas psicólogas, as quais nos acompanharam durante as visitas no hospital.

Em meio as nossas primeiras andanças, a frase de uma enfermeira com atuação no Bloco Cirúrgico ficou reverberando em nossos corpos. Disse ela: "Muitas vezes a gente precisa virar meio macho, para conseguir dar conta de algumas coisas no trabalho”.

Por entre tal reverberação, fomos sendo provocados ao longo de nossas andanças pelo hospital a termos um olhar atento para o setor do bloco cirúrgico. Fomos sendo interrogadas no como ocorrem as microgestões do trabalho em meio ao atravessamento do gênero sob corpos que estão "vulneráveis" e à mercê da manipulação cirúrgica.

Assim, elegeu-se o bloco cirúrgico como área a ser abrangida pela pesquisa. Procedemos a reuniões com a coordenação do Bloco e demais trabalhadores e trabalhadoras para apresentação da proposta da pesquisa, realizamos visitas sistemáticas ao setor para o acompanhamento dos processos de trabalho, especialmente nos procedimentos cirúrgicos. Realizamos ainda, a constituição de um grupo com 11 
trabalhadores e trabalhadoras para realização da análise do trabalho como atividade junto aos técnicos e técnicas de enfermagem, tendo em vista que estes estão presentes desde o início até o fim dos procedimentos cirúrgicos.

O primeiro movimento produzido, nos encontros de grupo, voltou-se para a colocação da problemática da pesquisa com os técnicos e técnicas de enfermagem de modo a fazer circular a temática trabalho e gênero, na tentativa de produção de uma demanda de análise entre os trabalhadores e trabalhadoras na direção da proposta da pesquisadora. Nesta direção, as formulações apresentadas pelos trabalhadores e trabalhadoras se referiam a exposição dos corpos em alguns procedimentos cirúrgicos, como evidencia a fala de uma técnica de enfermagem " $\mathrm{Na}$ gineco todo mundo toca, todo mundo passa a mão. É uma agressão".

$\mathrm{Na}$ sequência, elegemos três procedimentos cirúrgicos a serem analisados junto aos trabalhadores e trabalhadoras, a saber: ginecológico, urológico e traumatologia de quadril. Acompanhamos os procedimentos eleitos, observando, enquanto pesquisadora, e descrevendo o modo como processos eram realizados. Após colocamos os aspectos observados em debate, nos cinco encontros Rev. Polis e Psique, 2021; 11(3): 184 - 206 coletivos, com objetivo de acessar a atividade.

De acordo com os investimentos do método da Clínica da Atividade, torna-se fundamental o acompanhamento dos processos de trabalho, no modo como, no ato o trabalho, as ações são realizadas. A proposta metodológica consiste em uma coanálise do trabalho, praticada no ambiente habitual, considerando que o analista do trabalho é precedido neste ambiente por aqueles e aquelas que ali exercem seu ofício. Sendo assim, a análise do trabalho deve considerar a experiência dos trabalhadores e trabalhadoras, tomando como ponto de partida a experiência concreta do trabalho. Desse modo, busca intervir no sentido de provocar os trabalhadores e trabalhadoras a acessarem uma experiência já vivida, enquanto trabalho realizado e, a partir dela, ter meio de viver outras experiências (Clot, 2006).

Em convergência com o método da clínica da atividade, a Praxiografia consiste em um fazer metodológico, no qual o pesquisador ou pesquisadora em exercício, encontra-se imerso ativamente no cotidiano da pesquisa. Refere-se a um modo de investigar, ou seja, um modo de olhar os actantes em pesquisa. Porém, ao contrário das perspectivas de observação que supõe um observador ou observadora, 
a Praxiografia supõe uma pessoa na posição de pesquisador ou pesquisadora que transita pelo local de estudo, participa de algumas de suas atividades, conversa com as pessoas que por ali circulam e descreve as práticas que chamaram sua atenção. Nesse sentido, caracteriza-se por uma ênfase em acompanhar as práticas e seus efeitos (Mol, 2002).

Considerando a intercessão entre os investimentos da clínica da atividade que visa acessar a processualidade do trabalho em ato e do método praxiográfico, no sentido de se atentar para o modo como os objetos estão sendo feitos nas práticas, consideramos potente utilizar como dispositivo para o acesso da análise do trabalho como atividade, as observações e descrições da realidade, o que é proposto por Mol (2002). Nesse sentido, propomos aos trabalhadores e trabalhadoras que acompanharíamos os procedimentos eleitos, observando e descrevendo o modo como o trabalho vinha sendo feito, para que, após, colocássemos os aspectos observados em debate nos encontros coletivos, com objetivo de acessar a atividade.

Além da descrição dos processos, pretendíamos realizar a produção de imagens, tais como fotografias e/ou filmagens, conforme indicam os métodos de autoconfrontação ${ }^{9}$ e praxiografia, o que não se viabilizou dadas impossibilidades para tal, argumentadas pelos cirurgiões.

A leitura dos procedimentos foi realizada pela pesquisadora no grupo de técnicos e técnicas de enfermagem e ativou a análise da atividade dos trabalhadores e trabalhadoras que estavam presentes nos procedimentos, os e as quais passaram a referir-se ao modo como fizeram/fazem o trabalho. Ativou também a análise de atividade dos demais presentes, os quais remeteram a situações outras vividas no cotidiano de trabalho.

\section{Por entre prescrições e renormatizações: a produção do gênero pelas práticas de cuidado em saúde}

Acompanhar, auxiliar, circular, checar, cobrir, encaminhar, esterilizar, executar, instrumentar, monitorar, notificar, organizar, posicionar, preparar, prover, receber, registrar, remover, verificar... São muitos os verbos que compõem o trabalho prescrito dos técnicos e técnicas de enfermagem de um bloco cirúrgico, desde o plano impessoal de seu oficio - naquilo que as prescrições definem como tarefas a serem cumpridas. 
Frente aos dramas vividos, é na fronteira com o outro, que resistências e renormatizações são forjadas, num campo de relações possíveis entre os técnicos e técnicas de enfermagem, entre os técnicos e técnicas de enfermagem e os demais trabalhadores e trabalhadoras do bloco cirúrgico e do hospital, entre os técnicos e técnicas de enfermagem e os e as pacientes, atravessado por múltiplas normas e instituições. É na atividade que as normas de trabalho, e também de gênero que atravessam esse fazer, podem ser colocadas em questão, produzindo desvios e renormatizações, abrindo brechas e críticas a modelos regulatórios e também violentos que ancoram as práticas.

Por um lado, o trabalhador ou trabalhadora se vê pressionado ou pressionada a seguir o prescrito do trabalho (posicionar os corpos dos pacientes e auxiliar os médicos) e pode acabar produzindo ações pela via da produção de violência sobre eles. Por outro, na atividade, face ao vazio de normas, renormatiza o trabalho a partir de um plano de valores. Entretanto, muitas dessas renormatizações, sem o amparo do coletivo, colocam o trabalhador ou trabalhadora sob o risco da transgressão.O mesmo trabalhador-homem complementa trazendo uma situação que havia Rev. Polis e Psique, 2021; 11(3): 184 - 206 acontecido recentemente: "Porque eu sei que para mulher é bem mais difícil e nas salas que eu tô geralmente tem mais homens, tá. Tipo hoje, aconteceu o que a gente já tinha comentado que eu não acho certo, mas o anestesista mandou. Posicionar antes de entubar. Eu acho errado a posição ginecológica posicionar uma mulher antes de entubar. Mas ele [anestesista] mandou eu fazer. A gente acatou e fez. Que que acontece: posicionei e cobri. Na Hora! Porque cara, tinha... quantos? [...]Vários homens ali! Ela era uma senhora, eu fiquei constrangido por ela, entendeu? Não contestei nada. [...]. E eu sempre espero para posicionar depois que tá tudo pronto e eu pergunto para o anestesista se eu posso, porque eu não vou mexer no paciente..." Nesse lastro, outro trabalhador-homem se manifesta e diz o modo como faz o trabalho: "Só mexe depois que tá sedado, né”, seguido da resposta do outro trabalhador no modo como o trabalho tem que ser feito: " $E$, sempre. Eu acho legal isso. Mas ai "pode posicionar". "Pode?" Ela acordada tudo...".Uma trabalhadora-mulher prossegue justificando tais entraves: " $E$ ' que, às vezes, no querer agilizar as coisas, vem do anestesista, isso, sabe. 'Pode posicionar'. Antes, sabe? seguida da fala de outra trabalhadora-mulher contestando 
tal prática em outros procedimentos cirúrgicos: "Mas é mais nas 'uros' que posicionam depois. Porque na 'gineco'o paciente tá acordado e tão posicionando". Um trabalhador-homem se coloca justificando tal procedimento no trabalho: "Não, pois é, isso é metodologia deles [ginecologistas]'.Seguido de uma explicação por uma trabalhadora-mulher: Sabe por que? Porque até quando a mulher vai no 'gineco', a mulher tá consciente, ela não tá anestesiada e ele pede para colocar as pernas em posição ginecológica.Outras trabalhadoras e outro trabalhador complementam em relação a essa gestão do corpo das mulheres: " $E$ isso acaba sendo uma coisa tão normal" (trabalhadora-mulher). " $E$, não é por mal! É um hábito de 'gineco",". (trabalhadoramulher). "Mas eu acho que é uma coisa cultural [...] Porque mulher... claro mulher já é mais exposta, vai lá no ginecologista, então é normal 'abrir as pernas", (trabalhador-homem).

Uma das prescrições dos técnicos e técnicas de enfermagem é seguir os comandos dos cirurgiões e cirurgiãs e anestesistas nos procedimentos cirúrgicos. No entanto, essa prescrição é colocada em questão e renormatizada como possibilidades de desvio, de produção de cuidado em meio a situações de exposição dos corpos das mulheres, mesmo que a organização do trabalho não seja efetivamente transformada.

Face às infidelidades do meio, os técnicos e técnicas de enfermagem buscam recursos possíveis na produção de um cuidado que, por ora, recaem em um constrangimento, mas que servem de impulso para que produzam meio para tratar os e as pacientes de modo que não se sintam ainda mais violentados ou negligenciados. Além disso, recorrem a um universo de valores gerado no debate de normas de trabalho e de gênero, com suas lutas e demandas, interferindo e enfrentando aquilo que lhes contradiz em meio à atividade de trabalho.

Ao nos reportarmos ao procedimento urológico realizado com o paciente homem, não houve manifestações durante a leitura da descrição, sendo interrogada pela pesquisadora no final se teriam algo a colocar sobre esse processo de trabalho. A sala permanece em silêncio por alguns instantes, sendo este silêncio interrompido pela fala de um trabalhador-homem: "Rotineiro". Seguido do apoio de uma colega: “É bem rotineiro". Mediante tais colocações pontuais, a pesquisadora retoma uma questão discutida em 
encontros coletivos anteriores, referindo que os trabalhadores e as trabalhadoras haviam colocado que nos procedimentos urológicos os pacientes sentiam-se melhor quando havia homens trabalhando em sala. Uma trabalhadora-mulher responde: “ $E$, homem com homem fica mais à vontade. [...] E mulher com mulher”. Nessa direção, um trabalhador-homem verbaliza: “ $E a$ mulher não dá tanta bola. Se tem homem, mulher não dá tanta bola”. Uma trabalhadora-mulher discorda: "Depende. As novas não dão bola, mas as senhoras dão [...] Mas as novas não. Nesse momento, uma trabalhadora-mulher intervém: "Mas independentemente, eu acho que tem que ser mulher com mulher e homem com homem". Diante da impossibilidade de estarem em salas de modo sintônicos ao gênero, conforme o desejo expresso em suas falas, os próprios trabalhadores e trabalhadoras criam meios para agenciar tais situações: "Quando é uma menina, e tá eu e o [colega], por exemplo, o [colega] deixa para eu monitorar ela. E se é ao contrário ele que fica mais perto do paciente”. Outra trabalhadora complementa: “É a gente não aprendeu isso no técnico. Não foi direcionado por eles aqui dentro. É tu se colocar no lugar do paciente, sabe”.
Em meio a essas discussões levantadas nos debates acerca dos processos operativos no trabalho referentes à produção do cuidado dos corpos, colocamos em xeque o quanto os técnicos e técnicas de enfermagem operam em meio ao agenciamento das normas sociais (produção dos modelos regulatórios, gestão e controle dos corpos) por entre o exercício da normatividade vital recorrendo constantemente à criação e à instauração de novas normas vitais, de criação de novas formas de trabalho e de vida (Canguilhem, 1995), na medida em que criam meios para que os corpos, principalmente os das mulheres, sejam menos expostos e violentados em meio aos procedimentos cirúrgicos.

É, portanto, um modo de pensarmos a dinâmica da vida para além do dado, do estático e do modelo mecanizado da normalidade. Se os corpos se tecem encarnando normas regulatórias de gênero, estes também resistem pela subversão delas. Se os corpos são construções político-culturais, são também construções político-éticas (Machado; Vasconcelos; Melo, 2012), na medida em que se lançam em um modo ensaístico de outras formas, produzindo novas normatividades (Canguilhem, 1995) e performatividades de gênero (Butler, 
2003), experimentando o descaminho de se fazerem outros em outros lugares. Para Georges Canguilhem (1995) a vida não está fadada a modelos pré-estabelecido das formas possíveis: sempre as extrapola, as desvirtua, transborda todos os parâmetros, desfazendo-as.

Por entre renormatizações, produções de "desvios" e resistências vão se forjando na relação entre os diferentes atores que compõe o trabalho no bloco cirúrgico em um hospital, engendrando o cuidado em saúde de modo generificado. $\mathrm{O}$ que convoca a estarmos atentos à produção de normas antecedentes e, ao mesmo tempo, aos vazios de normas que exigem renormatizações.Diante disso, implica reconhecer essa dimensão sempre inantecipável do trabalho, a qual convoca a decisões, microescolhas, que podem ser tomadas como criação em ato dos trabalhadores e trabalhadoras. Bifurcações que colocam em questão as normas de trabalho e de gênero que os atravessam e podem colocar, em cena, caminhos singulares e inventivos.

\section{Performatividade(s) de gênero(s)}

A partir da discussão realizada até aqui, iniciamos um debate acerca do gênero profissional do técnico e técnica de enfermagem em termos das limitações à sua construção e também de sua potência enquanto produtores de novas normas de trabalho e de gênero. Pretendemos colocar em questão também o quanto o gênero profissional é a atravessado pela produção do gênero, considerando que a produção do gênero profissional também é da ordem de uma performatividade implicada no jogo entre agenciamentos por entre normas sociais e normas vitais.

De acordo com os técnicos e técnicas de enfermagem, poucos são os espaços de encontro para análise dos processos de trabalho, e esses, quando ocorrem, têm por finalidade, especialmente, o repasse de informações e a colocação da necessidade do trabalho funcionar em meio à produtividade ${ }^{10}$ ficando de fora qualquer movimento que coloque em debate o processo normativo experimentado no trabalho. Além disso, a própria organização do trabalho não oferece o encontro entre eles e elas, pois os mesmos e mesmas trabalham geralmente em duplas, cada uma separada em cada sala cirúrgica. Por outro lado, movimentos no sentido de uma produção coletiva pela atividade no trabalho em saúde foram ganhando vida em alguns momentos ao 
longo de nossa pesquisa. No percurso da pesquisa, ao perguntarmos sobre como faziam para enfrentar os momentos difíceis e de discordância em meio aos procedimentos cirúrgicos, percebemos como um saber que emerge do compartilhar entre os pares no cotidiano de trabalho: "Gente, eu peguei isso dos colegas!" (trabalhador-homem).

A rede de cuidado é produzida pelos próprios técnicos e técnicas de enfermagem, sem contar necessariamente com o aval ou a medição de seus superiores hierárquicos, os quais emergem em meio ao estoque gerado pela atividade: “Todo mundo faz assim"(trabalhadoramulher). "É que um vai aprendendo com o outro, né. "ah olha só que legal o jeito que a [colega] fez, vou fazer assim”. Quando tu é novo [...] que nem as gurias são novas, as gurias podem dizer, elas se espelham na gente, né”. (trabalhadoramulher). "Quem chega vai pegando isso dos outros que já estão aqui. Porque não é legal deixar tudo aparecendo"(trabalhadora-mulher). Nessas situações, ocorre dos técnicos e técnicas acionarem essa rede informal compartilhada, afirmando que esses saberes não são repassados no curso técnico, tão pouca pela instituição.
Ainda que muitas vezes essas formulações coletivas se voltem apenas em algumas situações específicas, como a proteção à exposição do paciente e o cuidado no tratamento dos mesmos, nos parece haver espaço para a construção conjunta de uma ética no trabalho pelos debates acerca dos modos de gerir a produção do cuidado em meio ao debate de normas de trabalho e gênero. Essa iniciativa de apoio entre os técnicos e técnicas de enfermagem, sem interferência da organização ou das instituições de ensino, vão sendo renormatizadas em meio ao modo como vão aprendendo com os colegas mais antigos e antigas e produzindo assim, novas normas de trabalho e de gênero, indicam que o gênero profissional não como um conjunto de orientações a seguir, mas como um recurso para renovar o desenvolvimento da ação dos trabalhadores e trabalhadoras em meio à performatividade de trabalho e de gênero.

Chamamos a atenção para uma situação que se produziu como potente estratégia coletiva entre os próprios técnicos e técnicas de enfermagem, colocando em questão os possíveis em termos de fortalecimento do gênero profissional e também da produção de gênero, renovando o ofício, os quais, por 
vezes, se produzem como modos de resistência a certas estratégias prescritivas e assujeitadoras no trabalho.

Um aspecto importante refere-se a alguns movimentos na direção de construção de estratégias de proteção à exposição dopaciente, principalmente nos procedimentos ginecológicos: “Às vezes eles tiram até se o cirurgião tá paramentado já, por exemplo. Aí o anestesista diz: pode posicionar! Daí a gente posiciona. Daí a gente larga, tipo assim ou o lençol para baixo assim, ou bota uma compressa mesmo. Se o cirurgião tá ali esperando para pintar ali, fazer a assepsia e tira. Mas o anestesista não anestesiou ainda, a gente sempre recoloca ali, não deixa assim" (trabalhadora-mulher). "Isso é geral! Eu peguei esse hábito com os colegas." (trabalhador-homem). Desse modo, podemos pensar que os conhecimentos genéricos produzidos pela própria atividade, pela experiência no e pelo trabalho, emergem, como um recurso frente aos desafios do real em meio à performatividade de gênero, colocando em questão os atos de cuidado e de exposição dos corpos.

Retomamos assim, um dos importantes conceitos-operadores, pela perspectiva da atividade, que é o desenvolvimento do 'poder de agir', entrelaçado sempre coletivamente, que converge em saúde e resistência. De acordo com Clot (2010) o 'poder de agir' no trabalho está ligado diretamente a um movimento incessante entre a dimensão pessoal e transpessoal, entre gênero profissional do ofício e a estilização dos trabalhadores. Nesse ponto, sugerimos o quanto a performatividade de gênero compõe a história do ofício, na medida em que o gênero se arranja como um instrumento expresso principalmente pela cultura e pelo discurso que, por sua vez, dão legitimidade aos corpos.

Dizemos, com isso, que o gênero profissional ao formar um repertório de atos e maneiras de considerar as coisas e pessoas em determinado meio, que fixam de alguma maneira os previsíveis que permitem suportar os imprevisíveis do real, são atravessados e produzidos de modo generificado, operando na distribuição de poder por meio de atos corporais e de fala, que tendem a reificar normas regulatórias de gênero, bem como guardam a possibilidade de subversão das mesmas. Nesse sentido, podemos pensar que tanto o gênero profissional quanto a produção do 
gênero podem ser entendidos como ferramentas para ação.

\section{Do gênero à atividade, da atividade ao gênero}

Apostamos por esta pesquisa na construção de um caminho inventivo ao tomar a produção do gênero em meio a experiência do trabalho como atividade no trabalho em saúde em um bloco cirúrgico de um hospital. Olhar por essa experiência normativa pelo trabalho e pelo gênero nos possibilitou analisar por entre as microgestões cotidianas do trabalho, o modo como a produção do cuidado em meio à dimensão generificada.

As discussões empreendidas pela pesquisa apontam para um campo de trabalho sempre em movimento, em uma zona de tensão por entre as prescrições de trabalho em meio às normas regulatórias e a possibilidade de subversão das mesmas, em que os trabalhadores e trabalhadoras são convocados, cotidianamente, a criar meios para fazer o trabalho acontecer. Olhar a performatividade de gênero pela perspectiva da atividade, nos remete, sobretudo, a um plano de processualidade, de engendramento entre normas sociais e vitais, onde a produção de subjetividade e de realidades não cessam de ser (des)feitas Rev. Polis e Psique, 2021; 11(3): 184 - 206 em ato, no encontro entre trabalhadores e trabalhadoras, entre trabalhadores e trabalhadoras e os e as pacientes, que face aos desafios do real, são colocadas a prova e renormatizadas no e pelo trabalhar. Nessa direção, em meio a performatividade de gênero e a atividade do trabalho, os trabalhadores e trabalhadoras problematizam as normas de trabalho e de gênero, renormatizando as situações de trabalho, produzindo estilizações que podem se tornar recursos para os próprios trabalhadores e próprias trabalhadoras.

Colocamos esse processo de pesquisa como um desafio de pesquisa com os trabalhadores e trabalhadoras, tendo em vista que chegamos ao hospital com a nossa problemática de pesquisa, mas que foi aberta a constante composição e recomposição em meio a aquilo que lhes fazia questão no trabalho. No que refere a temática da pesquisa a fala de uma trabalhadora-mulher remente àquilo que lhe foi ativado em meio a proposição das análises: "É, e tu vê quantas questões a gente trouxe... Que é função dos médicos só querem os mais velhos, os guris porque são mais fortes e não querer as gurias. Tem a questão do racismo. A questão da classe social também, né. Tem tudo isso”.

Em meio ao processo do pesquisar, àquilo que não havíamos de início, 
enquanto pesquisadoras, pesquisar, emerge em meio a fala dos trabalhadores e trabalhadoras no tocante a outros marcadores sociais que atravessam o trabalho em saúde, como a questão racial e de classe. Diante disso, outras questões são por nós formuladas, tal como: de que modo os demais marcadores sociais da diferença, dentre eles raça, classe social, etnia, religião, também compõem as microgestões no trabalho como atividade?

A partir dessa pesquisa, apontamos a importância de produzir estudos relativos à produção do gênero em meio aos processos operativos do trabalho e indicamos a pertinência de ampliar os estudos no campo pela perspectiva da intereseccionalidade.

\section{Notas}

${ }^{1} \mathrm{~A}$ pesquisa de campo foi realizada pela primeira autora, para sua dissertação de mestrado.

${ }^{2}$ Pensamos a produção do gênero para além do masculino e feminino, conforme as articulações da Teoria Queer proposta por Butler (2003), a qual 'ultrapassa os gêneros' (transgendering), ao questionar a normatividade heterossexual e ressaltar o aspecto socialmente contingente e transformável dos corpos e da sexualidade (gays, lésbicas, transexuais, travestis, bissexuais, não binários).

${ }^{3}$ Constatamos que há poucas produções que abordam a temática trabalho e gênero pela perspectiva da Atividade. Nos estudos Rev. Polis e Psique, 2021; 11(3): 184 - 206 brasileiros, encontramos apenas dois artigos que exploram o trabalho por meio do conceito Atividade articulado com as questões de gênero, quais sejam: "Trabalho e Saúde Coletiva: o ponto de vista da atividade e das relações de gênero" (Jussara Brito, 2005) e "Saúde, subjetividade e trabalho: o enfoque clínico e de gênero" (Jussara Brito et al., 2012)5.As pistas apresentadas nos estudos desse grupo de pesquisadoras nos convocam a pensar a respeito do modo como ocorre o trabalho concreto de homens e mulheres em situação analisando os imbricamentos entre as normativas de gênero e de trabalho. Contudo, ainda que se refiram à dimensão normativa, as pesquisadoras não chegam a desenvolver analiticamente a produção do gênero que se dá por entre o trabalho como atividade, não se aproximando também, da discussão de gênero profissional e estilo.

${ }^{4}$ No campo da clínica da Atividade, Yves Clot discute o conceito de "gênero profissional", o qual falaremos mais adiante. Este conceito se distingue do gênero proposto por Judith Butler, ainda que exista uma nuance no que se refere à performatividade. Portanto, quando mencionarmos apenas a palavra "gênero" referimo-nos ao proposto por Judith Butler e quando citarmos "gênero profissional" referimo-nos ao proposto por Yves Clot.

${ }^{5}$ Para Clot (2010) o poder de agir refere-se a possibilidade de afirmação do ser, na potência de vir a ser, como modo de ser afetado no ambiente de trabalho, em que essa afetação vai além do simples poder de "realizar coisas", pois inclui a potência de ser ou não afetado, o qual expande as possibilidades de transformar a si mesmo e ao mundo.

${ }^{6}$ Por ofício, Clot (2013) entende não apenas uma prática, uma atividade ou uma profissão, mas de uma discordância criativa entre quatro dimensões (pessoal, interpessoal, transpessoal e impessoal) articuladas no processo laboral, através das quais o oficio se constitui em um elemento fundamental que conecta o trabalhador a atividade. $\mathrm{O}$ aspecto impessoal, correspondente à tarefa, e o transpessoal, correspondente ao gênero profissional, são os 
instrumentos da atividade, constituindo-se nos objetos que a antecipam. Já o pessoal e o interpessoal seriam as dimensões instituintes da atividade, reorganizando-a através de um retrabalho, tendo em vista que estas abarcam as dimensões instituídas da tarefa (impessoal) e do patrimônio social (transpessoal), rearticulando-as por meio dos estilos e da negociação coletiva (pessoal e interpessoal).

7 Produções de pesquisadoras Danielle Vasconcelos Teixeira e Maria Elizabeth Barros de Barros (2009, Autor (2018); Autor; Autor (2018).

${ }^{8}$ O Desenvolvimento Humano é um setor que faz parte de uma das "subáreas" que compõe o Recursos Humanos do Hospital. É responsável por todos os processos seletivos que ocorrem na organização. Além disso, realiza treinamentos, capacitações, grupos com equipes, acompanhamento de funcionários e funcionárias, priorizando sempre o desenvolvimento e a saúde mental dos trabalhadores e trabalhadoras.

9 Clot (2006) propõe o método de Autoconfrontação para a análise do trabalho como atividade, pelo qual os trabalhadores e trabalhadoras se veem em situação laboral por imagens, colocando em cena, nuances que dificilmente são percebidas quando vividas no tempo e no espaço real do trabalho.

${ }^{10}$ Uma importante contribuição de uma Clínica no e pelo Trabalho é deslocar o agir do fazer. Este último, atrelado aos diferentes mecanismos produzidos a fim de aumentar a produtividade, exige um trabalhador ou trabalhadora eficiente, capaz de respostas rápidas e tecnicamente competente. Já o agir não é simplesmente se deixar levar pela maré, nem simplesmente contrapor-se a ela já que a mera oposição é tão assujeitadora quanto a dominação, ao se colar na obrigação de perpetuar a norma. Desse modo, agir é (r)existir nas tramas do poder.

\section{Referências}

Butler, Judith. (2003). Problemas de gênero: feminismo e subversão da Rev. Polis e Psique, 2021; 11(3): 184 - 206 identidade. Rio de Janeiro: Civilização Brasileira.

Butler, Judith. (2002). Cuerpos que importan: sobre loslímitesmateriales y discursivos del "sexo".Buenos Aires: Paidós.

Barros, Laura Pozzana de; Kastrup, Virgínia. (2009). Cartografar é acompanhar processos. In: Passos, E.; Kastrup, Virginia; Escóssia, Liliane. Pistas do método da cartografia. Porto Alegre: Sulina.

Clot, Y. (2010). Trabalho e poder de agir. Belo Horizonte: Fabrefactum

Clot, Y. (2013) O ofício como operador de saúde. Cadernos de Psicologia Social do Trabalho. 16(spe), 1-11.

Clot, Y. (2011). Clínica do trabalho e clínica da atividade. In $P$. Bendassolli, \& L. A. P. Soboll (Orgs.), Clínicas do Trabalho novas perspectivas para compreensão do trabalho na atualidade (pp. 7183). São Paulo: Atlas.

Canguilhem, G. (1995). $O$ normal $e o$ patológico. 3 ed. Rio de Janeiro: Forense-Universitária.

Deleuze, G. \& Guattari, F. (1995). Mil Platôs: capitalismo e esquizofrenia. Vol. I. São Paulo: Ed. 34.

Faita, D. (2004). Gêneros de discurso, gêneros de atividade, análise da atividade do professor. In: Machado, Ana Rachel (org.). O ensino como trabalho: uma abordagem discursiva. São Paulo: Eduel, 2004, p. 57 - 80.

Mol, Annemarie. (2002). The body multiple: Ontology in medical practice. Durham and London: Duke University Press. 
Moraes, Marcia Oliveira; Arendt, R. J. J. (2013). Contribuições das investigações de Annemarie Mol para a psicologia social. Psicol. estud., 18 (2), Maringá, 313-321.

Paraíso, Marluce. (2011). Raciocínios generificados no currículo escolar e possibilidades de aprender. In: Leite, C. et al. (Orgs). Políticas, fundamentos e práticas do currículo (p. 147-160).Porto: Porto Editora.

Rocha, Marisa Lopes da \& Aguiar, Katia Faria. (2010). Entreatos: percursos e construções da psicologia na rede pública de ensino. Estudos $e$ Pesquisas em Psicologia, Rio de Janeiro, 13 (1), 68-84.

Sade, C., Ferraz, G. C. \& Rocha, Jerusa Machado. (2013). O ethos da confiança na pesquisa cartográfica: Experiência compartilhada e aumento da potência de agir. Revista Fractal, 25 (2), 281-298.

Teixeira, Danielle Vasconcelos \& Barros, Maria Elizabeth Barros de. (2009). Clínica da Atividade e Cartografia: construindo metodologias de análise do trabalho. Psicologia \& Sociedade; 21 (1): 81-90, 2.

Renata da Silveira Borstmann é mestra em Psicologia Social e Institucional pela Universidade Federal do Rio Grande do Sul - UFRGS. É também graduada em Psicologia pela Universidade de Santa Cruz do Sul - UNISC.

E-mail: renatasborstmann@gmail.com ORCID: https://orcid.org/0000-0001$\underline{9669-3742}$
Fernanda Spanier Amador possui graduação em Psicologia, especialização em Saúde Mental Coletiva, mestrado em Psicologia Social e da Personalidade (PUCRS) e doutorado em Informática na Educação (UFRGS).

E-mail: fernanda.amador@ufrgs.br

ORCID: $\quad$ https://orcid.org/0000-0002$\underline{7385-8900}$
Submissão: 06/10/2020

$1^{o}$ avaliação: $24 / 05 / 2021$

Aceite: $28 / 06 / 2021$ 